\title{
EL IMPACTO LOCAL DE UNA PRODUCCIÓN GLOBAL. LA REAL CASA DE MONEDA DE MÉXICO Y SUS PROVEEDORES, 1732-1821
}

\author{
THE LOCAL IMPACT OF A GLOBAL PRODUCTION. \\ THE ROYAL MINT OF MEXICO \\ AND ITS SUPPLIERS, 1732-1821
}

\author{
Felipe Castro Gutiérrez
}

Universidad Nacional Autónoma de México, ciudad de México, México, fcastro@unam.mx

\begin{abstract}
Resumen. Este artículo aborda el efecto de “derrama” de la Real Casa de Moneda en la capital de Nueva España, en razón de la construcción de instalaciones, adquisición de maquinaria y compra de insumos tales como combustible, animales de tiro y minerales no preciosos como el cobre. El autor sostiene que el establecimiento de la administración gubernamental directa, a partir de 1732, implicó la introducción de principios racionales en la contratación y supervisión de proveedores. Finalmente, propone que el estudio del impacto local del gasto público es un tema que podría abrir perspectivas de interés en la historia de la economía de sociedades premodernas.
\end{abstract}

Palabras clave: historia de México; Casa de Moneda; virreinato; efecto de derrama.

Abstract. This article discusses the spillover effects of the expenditure of the Royal Mint in the capital of New Spain, due to the construction of facilities, acquisition of machinery and purchase of inputs such as fuel, draft animals and non-precious minerals, as copper. The author argues that the establishment of direct government administration, in 1732, involved the introduction of modern principles of hiring and supervising contractors. Finally, the study proposes that the local impact of public spending is an issue that may present interesting possibilities for the history of economics in pre-modern societies.

Key words: Mexican history; Royal Mint; viceroyalty; spillover effect.

Fecha de recepción: 6 de septiembre de 2013. Fecha de aceptación: 4 de junio de 2014.

Am. Lat. Hist. Econ., año 22, núm. 1, enero-abril, 2015, pp. 7-34 


\section{INTRODUCCIÓN}

T a Real Casa de Moneda de México acuñó la cuantiosa producción minera del virreinato novohispano, respaldó las siempre exhaustas finanzas reales y generó el vasto caudal monetario que fluyó por los canales mercantiles del naciente capitalismo. En el siglo XVIII desplazó a la ceca potosina, en el virreinato peruano, como la mayor productora mundial de moneda, y el peso de a ocho mexicano llegó a ser el circulante más y mejor aceptado en las transacciones internacionales (Romano, 1998; Valdéz, 1987).

Los historiadores han prestado bastante atención a esta Real Casa (como también acostumbraban llamarla sus autoridades). Se han ocupado de sus aspectos institucionales (orígenes, ordenanzas y régimen de gobierno) (Céspedes, 1996; González 1997; Soria 1994a), de su producción (Céspedes, 1996; Herrera, 1994), y de la peculiar relación entre el establecimiento y los poderosos "banqueros" o comerciantes de plata (Hoberman, 1991; Pérez, 2003; Rosenmüller, 2008; Valle, 2011). Existe, sin embargo, otra posible perspectiva: el funcionamiento adecuado de esta manufactura necesitaba de la construcción de edificios, instalación de maquinaria, adquisición de herramientas y compra de insumos menores (combustible, animales de tiro o minerales no preciosos, como el cobre), mediante procesos similares a los de la otra gran manufactura real, la del tabaco (Deans, 1992). Esto nos lleva a las consecuencias locales del gasto público, tal como se expresaba en el pago a los proveedores. Debe distinguirse esta derrama (esto es, las externalidades generadas por una actividad microeconómica que afectan a terceros no involucrados directamente en ella) del efecto "de arrastre" como el de la minería de metales preciosos, que ha sido objeto de mucho interés por sus implicaciones macroeconómicas en el comercio y la agricultura. Es un tema que fue primeramente planteado por Elhúyar (1979) y en tiempos actuales estudiado por Sempat Assadourian (1998, pp. 18-32) e Ibarra (2010).

Obviamente, este efecto microeconómico resultaba particularmente notable en la ciudad de México y sus alrededores, aunque no se limitara a ella. Es un tema de historia económica, pero que tiene asimismo que ver con aspectos sociales, cambios políticos (notablemente, las primeras manifestaciones de las reformas borbónicas), tecnológicos (derivados de la introducción de maquinaria moderna) y administrativos (la creación de normas explícitas en el abasto de una gran industria). Hirschman (1973, pp. 104-110) construyó un influyente modelo de lo que denominó eslabonamientos, con particular mención de las industrias "satélite", que podría describir el caso. Por otro lado, su aplicación requeriría de adecuaciones en el contexto de una economía de antiguo régimen y de empresas que 
eran monopolios gubernamentales, que además tenían facultades judiciales sobre la operación de los contratos.

Como podrá apreciarse, no considero aquí el más notable y visible insumo de la producción de la Real Casa, esto es, los metales preciosos. En sus inicios, el establecimiento no adquiría esta principal materia prima: se limitaba a recibir el oro y la plata de los introductores y devolvérselos convertidos en moneda, con el correspondiente descuento por gastos de operación. Posteriormente, bajo la administración real, la ceca compraba el mineral de inmediato, y por consiguiente la moneda acuñada pertenecía a la Real Hacienda (Fonseca y Urrutia, 1978, vol. 1, pp. 187, 206). Los considerables recursos necesarios para estas operaciones no provenían del gasto corriente de la Real Casa, sino de un fondo revolvente, inicialmente de 1200000 pesos, aumentado posteriormente a 2000000 y en 1778 (a raíz de la incorporación del Apartado del Oro) a 2600000.

Hay varias razones para excluir estos costos de adquisición del metal precioso: empequeñecería el de todos los demás insumos, de manera que haría casi imposible comprender los efectos que son asunto de nuestro interés; el rango social y los recursos económicos de los vendedores (grandes mineros o comerciantes) eran muy distintos a los de los demás proveedores, y desde luego los introductores no tenían contrato alguno, sino que se presentaban a vender su mineral cuando mejor les convenía. No dependían, en este sentido, del establecimiento, aunque requerían de sus servicios.

\section{ETAPAS}

La Real Casa de Moneda de México fue fundada por una real cédula de 1535 y ha permanecido en operación, con diferentes denominaciones, hasta el presente. Es una muy notable continuidad institucional, con escasos paralelos en el mundo.

Su historia novohispana tiene dos periodos bien marcados. Inicialmente la ceca estuvo en manos de personas que habían adquirido los oficios (de tesorero, ensayador, tallador, guarda mayor, alcalde y merino), primero por merced real y luego mediante remate público, de manera vitalicia, enajenable y hereditaria. No eran propiamente hablando funcionarios, sino un conjunto de beneficiarios asociados en un proceso productivo, del que recibían porcentajes por cada peso acuñado. Lo mismo incluso ocurría con los obreros, que por esta razón no pueden tenerse como asalariados, aunque obviamente sus dividendos eran muy menores (Castro, 2008, pp. 59-63). La intervención de la Real Hacienda se limitaba a obtener ingresos por el remate y sucesión de los oficios, la recaudación del impuesto del señoreaje y cada tanto realizar alguna "visita" o inspección, encargada a los 
virreyes o algún otro jerarca de alto rango, principalmente para asegurarse de que no hubiera fraudes en la ley y peso de la moneda (Gómez, 1979).

Entre 1728 y 1732 la corona procedió, como una de las primeras (y poco atendidas) innovaciones de la nueva dinastía borbónica, a reorganizar la ceca mexicana. En ese último año tomó el control directo de la administración, embargó todos los oficios y nombró funcionarios que obedecían normas muy precisas y detalladas. El gobierno reconoció que los oficios habían sido obtenidos por remate público y eran propiedad de sus poseedores, por lo cual se procedió a pagarles 3\% anual, mientras se redimía el capital invertido. Las sumas devengadas por este concepto fueron cercanas a los 30000 pesos anuales, y continuaron entregándose hasta su final redención, en 1777 (Fonseca y Urrutia, 1978, vol. 1, pp. 144-145; Soria, 1994a, p. 108).

Otros cambios importantes fueron la creación de varios talleres o "salas" que permitieron la división y especialización de los procesos productivos (ensaye, fundición, prensado, acuñación); la introducción de nuevos procesos tecnológicos (sobre todo, grandes molinos mecánicos para aplanar las barras de metal y prensas "de volante" para acuñación) y la consiguiente ampliación del antiguo edificio, anexo al palacio virreinal. Durante este periodo, se cerró el control gubernamental sobre el ciclo productivo cuando se decretó en 1778 el embargo del Apartado del Oro, destinado a la separación de este metal y la plata, que en muchos reales de minas aparecían asociados. Hasta entonces esta lucrativa operación había estado en manos de los grandes comerciantes de la familia Fagoaga (Soria, 1994b). Es algo que coincide con la mejor época de la ceca, cuando la amonedación ascendió a sumas de vértigo (véase gráfica 1).

\section{LOS MONTOS: EL BRACEAJE}

¿Exactamente de cuántos fondos disponía la Real Casa de Moneda para su gasto en infraestructura, herramientas, insumos, servicios y trabajo? Era un concepto que en la época ya se tomaba en cuenta y estaba previsto por las ordenanzas. En España se pagaban 65 reales (o 2210 maravedíes) por cada marco de plata de ley de moneda (de once dineros y cuatro granos) entregado por el introductor. En el momento de la acuñación, se agregaba un real por el braceaje o costo de la labor, y otro por derecho de señoreaje. De esto resultaba una talla (o valor final del conjunto de monedas acuñados) de 67 reales. ${ }^{1}$

${ }^{1}$ En lo referente a la "ley" o fineza, la plata pura constaba de doce dineros, de los cuales cada uno tenía 24 granos; en el sistema actual la ley mencionada sería de 930.51 milésimos. En 


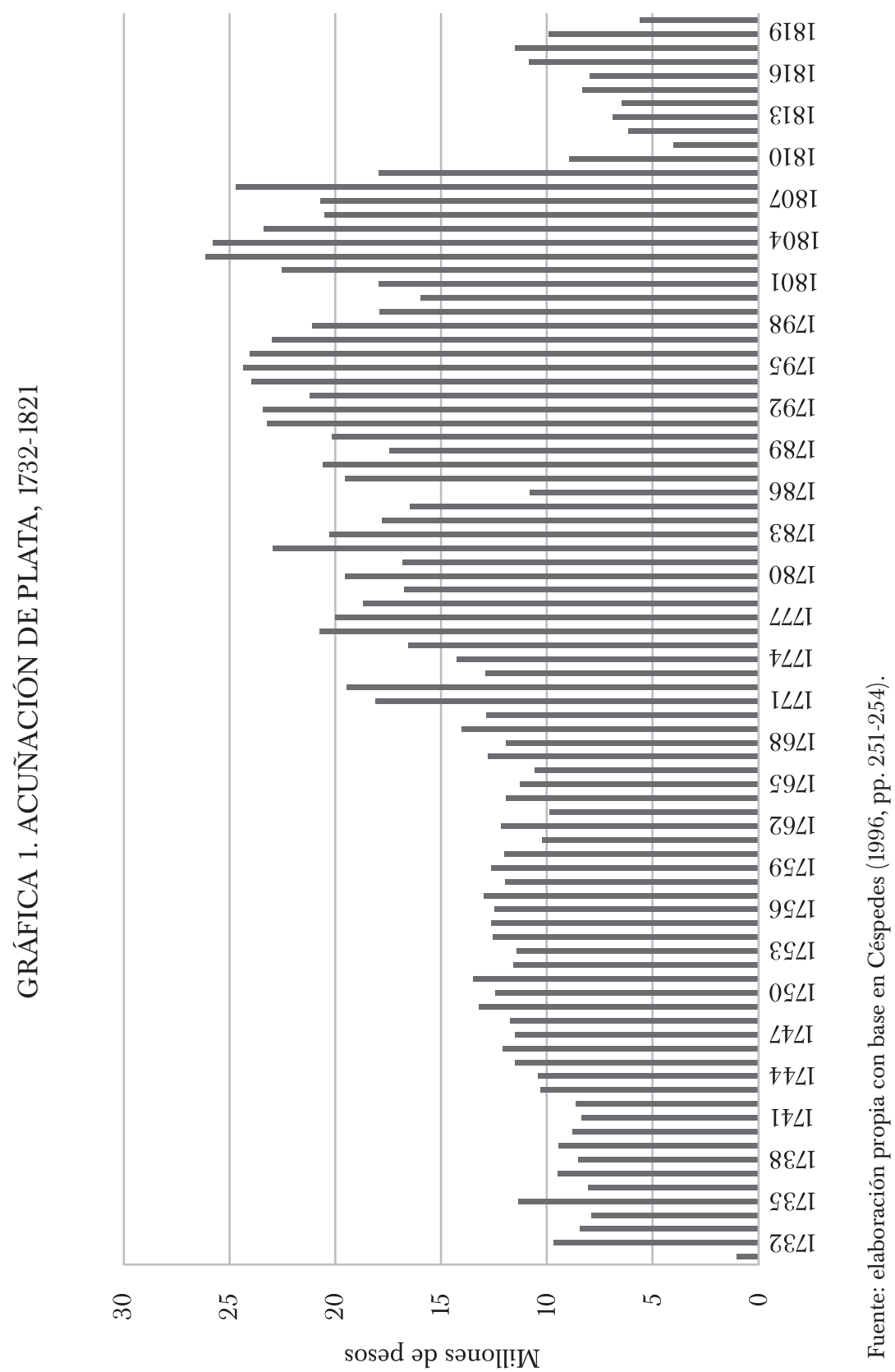


Las ordenanzas mexicanas originales mandaron pagar los mismos 65 reales al introductor, pero, ya que los gastos en las Indias eran "excesivos", se permitió que los oficiales se llevaran tres reales de derechos "hasta que más informados proveamos en ello lo que convenga". El fundamento es de interés, porque se dijo que de otra manera los oficiales "no podrían ni buenamente querrían labrar la dicha plata, por no tener congrua sustentación" (Encinas, 1945-1946, vol. 3, fs. 224-231). Céspedes (1996, pp. 80-81) atribuye al virrey Mendoza el mérito de lograr que los oficiales se contentaran con dos reales de braceaje. Esta situación dio lugar a que en 1567, cuando se ordenó el inicio del cobro del derecho de señoreaje, se dispusiera que habría dos reales por concepto de braceaje y uno por el nuevo impuesto, lo cual habría llevado la talla a 68 reales. Así consta en la Recopilación de leyes de los reynos de las Indias (1973, Ley 7, título 23, libro IV). Sin embargo, los tesoreros acostumbraban solicitar, como cláusula de sus contratos, que no se recaudara el señoreaje. ${ }^{2}$ Así, los gastos de producción estimados fueron de $2 / 67$, o sea, $2.98 \%$. Lamentablemente no hay cifras que nos permitan saber la cuantía de la acuñación en este periodo y, por derivación, el monto de los pagos que aquí nos interesan.

El señoreaje comenzó a cobrarse en 1616 (Elhúyar, 1979, pp. 2-3; Tepaske, 1976). Como de algún lado tenía que salir este real adicional, y es improbable que se descontara a los mineros (con quienes los oficiales de la Real Casa tenían lucrativos vínculos de interés), lo más seguro es que la talla pasara a ser entonces de 68 reales por marco (Orozco y Berra, 2004, p. 420). La relación del cobro del braceaje en relación con el valor nominal de la acuñación pasó a ser, por lo tanto, de 2.94 por ciento.

En 1698, el señoreaje comenzó a recaudarse de manera directa en las cajas de cada real de minas, lo cual debería haber llevado a que la talla regresara a 67 iniciales. Sin embargo, cuando José Diego de Medina Saravia entró a ejercer el oficio de tesorero, en 1713, encontró que la talla seguía en 68 reales, sin que nadie pudiera darle razón clara del origen y razón de esta situación. El real adicional se entregaba a quienes introducían la plata, una actividad que había llegado a estar prácticamente monopolizada por tres poderosos e influyentes "banqueros": Francisco de Valdivielso y Mier, Isidro Rodríguez de Lamadriz y Francisco de Fagoaga. El tesorero acordó con los demás oficiales representar esta situación al virrey en la primera ocasión posible, lo cual ocurrió cuando el marqués de Casafuerte visitó la institución en junio de 1723. En las ordenanzas revisadas ese año e impre-

cuanto al peso, la unidad era el marco de plata $(0.23 \mathrm{~kg})$, que se subdividía en ocho onzas, o bien en 4608 granos. Desde el punto de vista monetario, el peso de plata se dividía en ocho reales, cada uno compuesto (para efectos contables) por 34 maravedíes.

${ }^{2}$ Por ejemplo, en la confirmación de oficio del tesorero Juan Lorenzo Vera. Audiencia de México (vol. 183, núm. 64). Archivo General de Indias. 
sas el año siguiente, se declaró que la talla sería de 68 reales, por lo cual desde entonces tenemos constancia cierta. El caso provocó que en 1729, cuando el oidor José de Veytia realizó una visita a la Casa de Moneda, iniciara una causa criminal contra todos los oficiales, con prisión y embargo de bienes, así como en contra de los "banqueros" de plata, acusados todos de fraude a la Real Hacienda. ${ }^{3}$

La suma por concepto de braceaje fue entonces de $4.41 \%$ del total nominal acuñado (véase cuadro 1).

Existían también otros ingresos menores, como algunos pagos al ensayador, así como por la segunda afinación: cuando la plata introducida por los mineros no era de "ley de moneda", el establecimiento cobraba por su labor de "ajuste" unos ocho maravedíes por marco de plata. Asimismo, en 1679 comenzó la acuñación de moneda de oro, por la cual se recaudaban dos pesos por marco en derechos de braceaje. Flores (2008, p. 41) ha calculado que la acuñación de este metal era $3.8 \%$ de la correspondiente a la plata.

Se trata de sumas en conjunto considerables, aunque evidentemente no todos los ingresos se dedicaban a costos de operación. Buena parte se empleaba en la retribución de los oficiales, o sea en consumo cotidiano, gasto suntuario (esto es, en beneficio indirecto de plateros, sastres, pintores, albañiles), o bien en fundaciones y construcciones piadosas, lo cual en la época podía haberse estimado como una inversión tan necesaria como "productiva”. El caso más notable fue el de la cesión que hizo de su oficio el ensayador Melchor de Cuéllar a favor del convento carmelita del Santo Desierto de los Leones, cuyas utilidades se emplearon en lo sucesivo en sostener este edificio y comunidad de religiosos (León, 1922).

A raíz de las reformas instauradas progresivamente para establecer la administración real directa de la Casa de Moneda, hubo dos medidas relevantes para nuestros intereses. Por un lado, se rebajó la ley de la plata que se recibía de los introductores a once dineros, mientras que su pago se redujo a 64 reales y dos maravedíes (Elhúyar, 1979, pp. 14, 15). Por otro, debido a que se establecieron mayores exigencias en la calidad, en 1729 se introdujo para cubrir los eventuales costos adicionales un "real de aumento", elevando la talla (ahora sí formalmente) a 68 reales (o 2312 maravedíes). La recaudación de derechos en cada marco pasó a ser ahora de dos reales y 32 maravedíes por braceaje (o 100 maravedíes, 4.33\%), más un real de señoreaje (Zamora y Coronado, 1844-1849, vol. 1, pp. 29-30) (véase gráfica 2).

Estos derechos aportaron casi $90 \%$ de los ingresos. Otros rubros menores provinieron del llamado feble y de la acuñación de oro. Las mone-

\footnotetext{
${ }^{3}$ Casa de Moneda (vol. 391, exp. 1, fs. 1-160). Archivo General de la Nación, México.
} 
CUADRO 1. DERECHOS DE BRACEAJE, 1723-1728 (EN PESOS)

\begin{tabular}{lrr}
\hline Año & Acuñación total & Braceaje \\
& & \\
1723 & 2442351 & 107708 \\
1724 & 7012371 & 309245 \\
1725 & 6620563 & 291967 \\
1726 & 8866369 & 391007 \\
1727 & 3175063 & 140020 \\
1728 & 9092830 & 400085 \\
\hline
\end{tabular}

Fuente: elaboración propia con base en Céspedes (1996, pp. 251-254).

das acuñadas solían presentar cierta variación en su peso, tanto en feble como en fuerte, cuya tolerancia siempre estuvo regulada por las ordenanzas. Cuando la ceca pasó a la administración real, se ordenó que la desviación nunca "tocara en fuerte" y la diferencia pasó a ser un pequeño ramo más de los ingresos de la institución (Fonseca y Urrutia, 1978, vol. 1, pp. 239-240). Asimismo, con la expropiación del Apartado del Oro, por real cédula de 21 de julio de 1778, los correspondientes cobros de cinco reales y medio por cada marco de plata refinado pasaron a la Real Hacienda (Soria, 1994b).

Con el tiempo, las utilidades fueron cada vez mayores, puesto que una vez superadas las inevitables dificultades iniciales, la productividad fue incrementándose constantemente. Los sobrantes de estos vastos recursos iban para el gasto de la administración virreinal (en forma destacada, para los situados destinados a sostener las plazas militares en el Caribe) y para su envío a España "para las urgencias del real erario". En la práctica, las remisiones foráneas igualaron e incluso excedieron las utilidades, lo cual fue muy notable con la crisis fiscal de fines del siglo XVIII. Esto era posible porque se recurría (aunque estaba en principio prohibido) al fondo revolvente destinado a comprar plata y oro en efectivo, aunque fuese con el riesgo de afectar las operaciones (Soria, 1994a, pp. 159-168, 192-195; Marchena, 1979; Marichal, 1999). El caso más extremo ocurrió en 1809, cuando para pagar 3000000 de pesos al gobierno inglés, que debieron ser entregados súbitamente a un barco en Veracruz, no solamente se acudió a los fondos de la Real Casa de Moneda, sino que se determinó pagar temporalmente a los introductores tan sólo un tercio del valor de sus metales. ${ }^{4}$

El balance de la nueva administración de la Real Casa de Moneda en lo referente a sus contribuciones a la economía local fue ambiguo. El

\footnotetext{
${ }^{4}$ Casa de Moneda (vol. 78, exp. 8, fs 66-101). Archivo General de la Nación, México.
} 


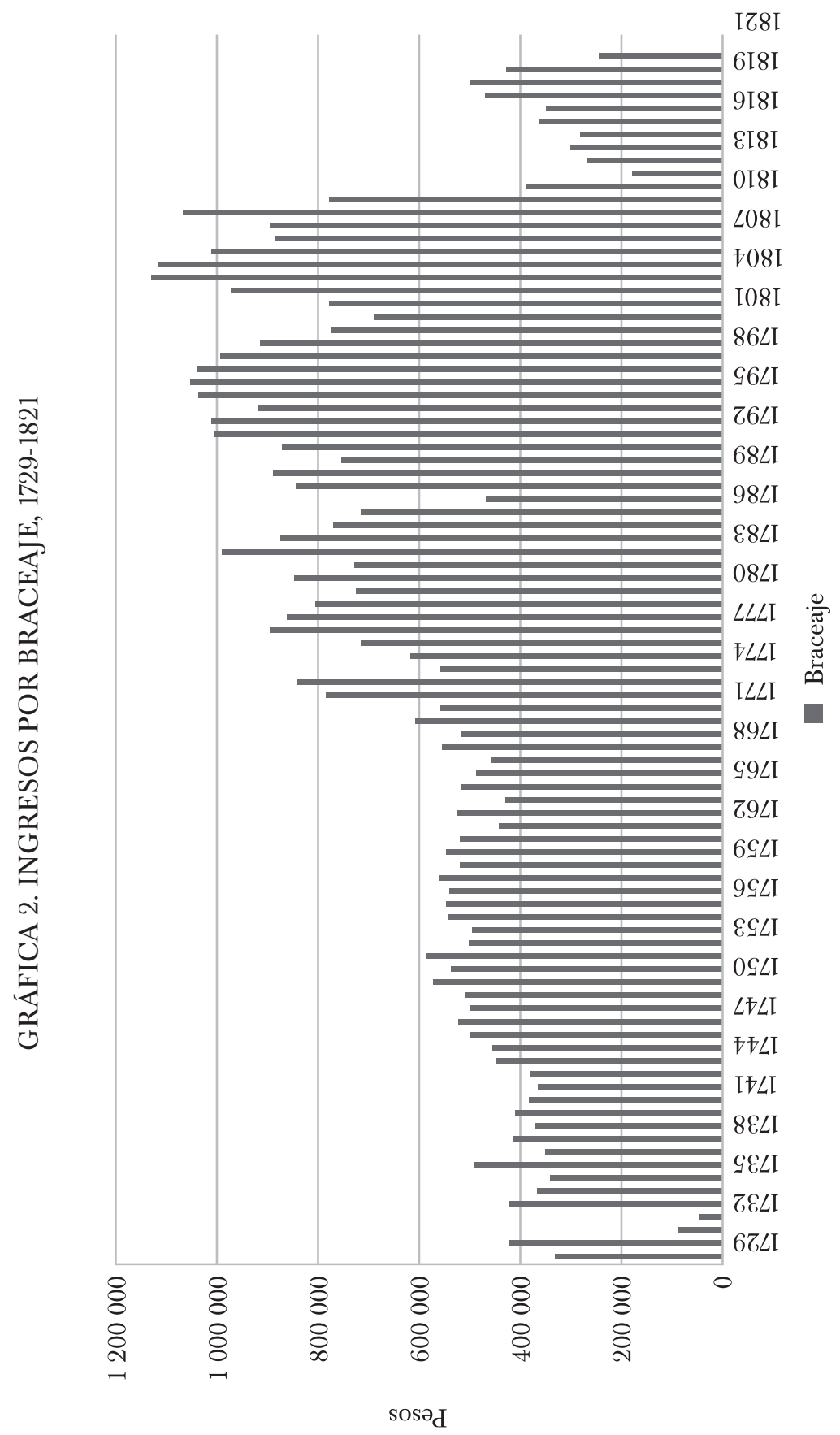

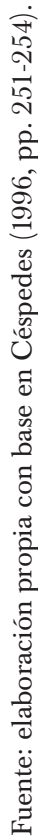


incremento notable de las operaciones redundó en obras materiales, adquisiciones de herramientas, equipo e insumos que beneficiaron a distintos productores y comerciantes. Por otro lado, fue en este periodo que la ceca se convirtió realmente en una institución colonial en el sentido económico del término, y mayores porcentajes relativos de los ingresos fueron canalizados hacia otras gobernaciones indianas y a la metrópoli, lo que no había ocurrido antes.

\section{LA DISTRIBUCIÓN}

Los pagos a los proveedores implicaban sumas de cierta consideración, lo que nos lleva a analizar más de cerca la forma en que estos ingresos eran distribuidos entre distintos actores económicos y sectores productivos.

En la etapa primitiva de la ceca no existía propiamente un departamento administrativo (la elemental contabilidad la realizaba el escribano) ni un presupuesto gubernamental para sostener los gastos. El tesorero y los demás oficiales recibían un porcentaje de las monedas acuñadas, así como raciones y otros derechos menores que eran "de costumbre", según una añeja y complicada tradición medieval (Castro, 2012, pp. 59-63). Con estos recursos, el tesorero adquiría insumos, pagaba el mantenimiento de las herramientas y de las instalaciones en general. El ensayador, por su parte, cubría los gastos de adquisición y cuidado de su equipo. El tallador tenía a su cargo las herramientas de su arte, la compra de acero, el pago de un maestro herrero y de sus ayudantes. El escribano compraba la papelería, plumas, tinta, cuadernos de contabilidad y otros artículos de su oficina, además de pagar el salario de un amanuense. Todo esto lo hacían según su buen criterio, sin necesidad de dar razón ni cuenta.

A partir de la "nueva planta", la distribución de responsabilidades siguió una racionalidad jerárquica, con procesos consecutivos y redundantes de supervisión para asegurar el buen uso y evitar todo desvío del erario real. Había un cuadro administrativo con estatutos, competencias y jerarquías. Los funcionarios eran retribuidos con un salario (y no con porcentajes de la producción), formaban parte de un escalafón en el que ascendían por méritos y antigüedad, estaban sujetos a una disciplina y vigilancia, y podían ser sustituidos o ubicados en otro puesto cuando conviniera. Corresponde bien, en este sentido, a la "administración burocrática", definida por Max Weber (1984), aunque en la práctica hubiera algunas clientelas políticas (por ejemplo en el nombramiento de superintendentes, que en general fueron letrados sin particulares conocimientos técnicos o administrativos) o inevitables favoritismos y parentescos entre los oficiales (Castro, 2012). La única y notable excepción fue la fielatura, donde se "imprimía" 
o acuñaba la moneda, que corrió por un contrato (no por venta del oficio) hasta $1762 .{ }^{5} \mathrm{El}$ resto de las actividades, con sus beneficios o quebrantos, corrieron por cuenta de la Real Hacienda.

Las ordenanzas preveían que el director o superintendente estuviera a cargo de la compra de metales preciosos (que se guardaban en un cofre, en una sala cerrada con llave) y otros gastos relevantes, con el auxilio del contador. Podía autorizar pagos extraordinarios que no excedieran de 200 pesos, pero si la cantidad era mayor, debía obtener la autorización del virrey, quien la otorgaba después de pedir la opinión del fiscal de Real Hacienda. Era el caso sobre todo de obras muy costosas, donde se pedía el dictamen de peritos y el parecer de los jefes de cada taller, así como del contador, para que finalmente el tesorero emitiera una orden de pago o libranza. De todo quedaba constancia en los libros de contabilidad, que pasaban por un cotejo e inspección a fin de año. Los oficiales tenían que pagar de su bolsillo cualquier cantidad no justificada debidamente (Fonseca y Urrutia, 1978, vol. 1, pp. 249-250).

Las adquisiciones de insumos menores estaban a cargo del guardamateriales. Era un funcionario de segundo nivel, pero muy importante para los proveedores porque era con quien trataban de manera cotidiana. Debía ser, según las ordenanzas, "persona desinteresada, de puridad de conciencia y de conocido honrado proceder, con inteligencia en las cosas que se necesitan para el servicio de la casa en las fundiciones, afinaciones y beneficios de tierras y escobillas". Se ocupaba de las compras necesarias para esos talleres, registrando todos los gastos escrupulosamente en un libro foliado. Administraba, para ese fin, dos bodegas y una carbonera, sin más vigilancia que la general de la ceca (que, por otro lado, era bastante estricta). Los gastos extraordinarios, o que excedieran de 50 pesos, debían ser aprobados previamente por el superintendente o (en la práctica) por el contador (Fonseca y Urrutia, 1978, vol. 1, pp. 273-274).

Aunque no aparecía formalmente en las ordenanzas, el guardamateriales era quien vigilaba la regularidad y calidad de los insumos, y de ocurrir problemas reiterados daba cuenta al superintendente quien, en su caso, podía iniciar procedimientos legales en contra del proveedor. Todos los registros contables pasaban finalmente al virrey, quien los remitía al Tribunal de Cuentas para su dictamen y aprobación. En principio, era un procedimiento a prueba de errores y de posibles actos de corrupción. Las ordenanzas aplicables fueron las de Medina del Campo (desde 1497), previstas obviamente para las cecas españolas (Recopilación, 1982, libro V, título 21) y las dadas para México por el virrey Antonio de Mendoza (Encinas,

\footnotetext{
${ }^{5}$ Casa de Moneda (vol. 663, exp. 169, 2 f) y (vol. 492, exp. 679, 8 f). Archivo General de la Nación, México.
} 
1945-1946, vol. 3, p. 225). Para el periodo de administración gubernamental, el marco normativo incluyó las Ordenanzas de Cazalla, elaboradas en $1730,{ }^{6}$ y las "Ordenanzas para el gobierno de la labor de monedas, que se fabricasen en la Real Casa de Moneda de México y demás de las Indias", de 1750 (Fonseca y Urrutia, 1978, vol. 1, pp. 221-283).

Más que contentarse con las riesgosas intermitencias de la libre oferta de estos insumos, la ceca prefería realizar contratos formales con distintos proveedores (que, dado el volumen de adquisiciones, pasaban a ser económicamente dependientes del establecimiento). Para la adjudicación, se procedía a un concurso público, el dictamen de peritos y la preferencia por la propuesta que asegurara el buen precio, la calidad y la confiabilidad del abastecimiento.

La Real Casa de Moneda era una empresa privilegiada por la corona. El superintendente era titular de un juzgado privativo, con jurisdicción exclusiva sobre todos los asuntos monetarios. Este aspecto se manifestaba muy bien en los contratos, donde la institución siempre se aseguraba el máximo de beneficios y el mínimo de obligaciones. De hecho, el incumplimiento del contratista podía derivar en un juicio, embargo de bienes e incluso en su prisión en la estrecha e insalubre cárcel situada junto a la entrada, donde montaba guardia un piquete de soldados. Aun así, era buen y deseable negocio proveer a la ceca, tanto por el carácter masivo de sus adquisiciones como porque, contrariamente a lo que ocurría en el ámbito empresarial novohispano, era un cliente que pagaba de inmediato, sin dilaciones, excusas ni pretextos. Y, además, por tener como destino una manufactura real, todos los materiales necesarios para la acuñación (no solamente la plata o el oro) estaban exentos de alcabalas, lo cual ahorraba trámites y malos ratos en las garitas aduanales ubicadas en las entradas de la ciudad.?

Una revisión detallada de la adquisición de cada insumo (incluyendo resmas de papel, tinta, aceite de nabo para las lámparas, ornamentos para la capilla, etcétera) sería excesivamente prolija, puesto que en muchos casos se trataba de operaciones menores, de unos pocos pesos. Aquí me concentraré en varios rubros de particular importancia: infraestructura, maquinaria, combustible, fuerza motriz, así como en algunos materiales de mayor relevancia, como el cobre.

${ }^{6}$ Casa de Moneda (vol. 270, exp. 3, fs. 256-346). Archivo General de la Nación, México.

${ }^{7} \mathrm{El}$ superintendente de aduanas intentó cobrar el impuesto en todo insumo que no tuviese relación directa con la acuñación. El superintendente de la ceca, Pedro Núñez de Villavicencio, replicó que todos eran por igual necesarios, y debían estar exentos. Así lo aceptó el virrey Bucareli. Casa de Moneda (vol. 107, exp. 6, fs. 130-139). Archivo General de la Nación, México. 


\section{OBRAS DE INFRAESTRUCTURA}

No tenemos descripciones del primer edificio construido a partir de 1570 bajo la dirección del maestro Miguel Martínez. En 1693 tenía dos patios: en el principal se hallaban ocho fundiciones u "hornazas", la sala de acuñación, la de balanza, fundición de desperdicio o "cizalla", y una carbonera. En el segundo se encontraban las oficinas del tesorero y del ensayador, el taller de la primera fundición (donde se realizaban afinaciones de las platas que no tenían la ley adecuada) y el tesorillo o almacén donde se guardaba el metal precioso. ${ }^{8}$ A partir del inicio de la administración real se llevaron a cabo en distintos momentos obras de diversa cuantía, de las que aquí mencionaré las más importantes.

Las transformaciones institucionales, la introducción de maquinaria y la separación de procesos industriales obligaron a una reestructuración de los espacios, que devino en la construcción de un nuevo edificio. La obra estuvo primeramente a cargo del ingeniero Nicolás Peinado y Valenzuela, director de la "nueva fábrica" de la moneda. Su intervención fue mal vista por los arquitectos novohispanos, que se veían privados de jugosos contratos y desplazados por alguien que no era de su oficio. Cuando el superintendente José Fernández de Veytia Linage pidió la opinión de varios peritos, la respuesta fue muy crítica tanto sobre la estructura como respecto de la simetría y belleza de la obra realizada. Se presentaron varios proyectos alternativos de correcciones y se escogió el de José Eduardo de Herrera para la fachada, y para los interiores al ingeniero militar Luis Diez Navarro (Flores, 2007, pp. 50-57). En 1734, el virrey arzobispo Vizarrón y Eguiarreta finalmente realizó la inauguración formal, con cierta pompa y ceremonia. Se había previsto que el costo fuese de 206000 pesos, pero en total se gastaron 449000 pesos, una situación que se repetiría en adelante (Fonseca y Urrutia, 1978, vol. 1, pp. 135-136; Soria, 1994a, pp. 26-27).

A la larga, se vieron defectos y también el crecimiento de la producción fue tal que los talleres disponibles fueron notoriamente insuficientes. Por ejemplo, la fundición del oro no tenía un lugar propio, y el reciclado de las tierras y escobillas (los desechos diversos de la producción, donde algo de metal podía recuperarse) acumulaba un rezago de varios años. Asimismo, la llegada en 1778 de Gerónimo Antonio Gil, con la misión de modernizar el grabado de los cuños y crear una escuela de artistas de ese ramo, demandó mayores espacios. De todo resultó, como informaba el superintendente Núñez de Villavicencio, "incomodidad, tardanza y estrechez". 9

\footnotetext{
${ }^{8}$ Casa de Moneda (vol. 333, exp. 3, f. 63). Archivo General de la Nación, México.

${ }^{9}$ Casa de Moneda (vol. 360, exp. 8, fs. 74-78). Archivo General de la Nación, México.
} 
Así, en 1779 el ingeniero militar Miguel Constanzó recibió la comisión de construir, en terrenos del palacio virreinal, varios talleres para las oficinas de la talla (donde se preparaban los cuños y troqueles empleados en la acuñación), la academia de grabado, viviendas de su director, salas para el gabinete o museo de arte, y bodegas para leña, carbón, paja y otros materiales combustibles que no debían estar cerca de las "oficinas de fuego" por el riesgo de incendios. Constanzó fue uno de los ingenieros-arquitectos "modernos", promotores del nuevo estilo neoclásico y el favorito de sucesivos virreyes y prelados. Había ya participado en estos años en la adecuación del Hospital de San Andrés, y después se ocupó de varios edificios religiosos, como el atrio del convento de la Encarnación (Moncada, 1994). Constanzó estimó el presupuesto en 47934 pesos, y la obra se terminó en 1783 , aunque con un considerable incremento en los costos. ${ }^{10} \mathrm{El}$ fundidor mayor, Pablo de Sequeiros, para no ser menos, expresó que sus oficinas eran estrechas y que las nuevas construcciones habían quitado parte del espacio de sus dos fundiciones, la de San Joseph y la de Nuestra Señora de Guadalupe. Con este fin pidió una ampliación, misma que fue aprobada con un costo de 25412 pesos. $^{11}$

Casi al mismo tiempo, en 1778, se incorporó el Apartado del Oro, para lo cual fue necesario comprar el edificio a los anteriores dueños (Francisco y Juan Bautista Fagoaga) en 43021 pesos. ${ }^{12}$ Años después se requirieron adecuaciones mayores, porque por la mala ventilación en los hornos había fallecido un trabajador por intoxicación. Las obras estuvieron a cargo del arquitecto Antonio Velázquez, con un costo de 24140 pesos. ${ }^{13}$ En 1808 se determinó asimismo poner nuevos hornos de destilación y hornillas de apartar metales, estimados por el arquitecto Manuel Tolsá con un valor de 71150 pesos. ${ }^{14} \mathrm{Y}$ en 1811 se construyó, también por Tolsá, una nueva oficina de beneficio de tierras, valuada en 38830 pesos..$^{15}$ Tolsá es el más conocido arquitecto neoclásico, fue autor de numerosas obras que contribuyeron a darle a México el nombre de Ciudad de los Palacios. Entre ellas se hallan dos vinculadas con el tema de este artículo: el Palacio de Minería y el del marqués del Apartado (Uribe, 1990).

${ }^{10}$ Casa de Moneda (vol. 355, exp. 4, fs. 59-115) y (vol. 308, exp. 7, fs. 22-27). Archivo General de la Nación, México.

${ }^{11}$ Casa de Moneda (vol. 220, exp. único, fs. 2-5). Archivo General de la Nación, México.

${ }^{12}$ Mayorazgos (vol. 8, exp. 6, fs. 29-30). Archivo General de la Nación, México.

${ }^{13}$ Casa de Moneda (vol. 302, exp. 17, fs. 382-395). Archivo General de la Nación, México. Velázquez fue primer director de arquitectura de la Real Academia de San Carlos. Su principal obra fue una capilla en Santa Teresa la Antigua, y mayormente se ocupó de adecuaciones y ampliaciones en distintos recintos religiosos. Véase González (1991).

${ }^{14}$ Casa de Moneda (vol. 121, exp. 8, fs. 94-107). Archivo General de la Nación, México.

${ }^{15}$ Casa de Moneda (vol. 465, exp. 5, fs. 17- 39). Archivo General de la Nación, México. 
Los costos iban a materiales de construcción (sobre todo piedra tezontle, procedente de las canteras de San Francisco Tlaltenco, al sur del Valle de México), primas y honorarios de los arquitectos, de sus sobrestantes o capataces, jornales de maestros albañiles, peones permanentes y eventuales, bodegueros, veladores y pagadores (o sea, administradores).

Las sumas mencionadas deben tomarse como indicativas, y en la práctica siempre rebasaban los montos previstos. En efecto, lo usual era que se pidiera a un maestro de obras o arquitecto conocido un "tanteo o cálculo prudencial" de los costos. Una vez presentado este presupuesto, pasaba a ser dictaminado por el contador y el superintendente, y finalmente se remitía al virrey, quien habitualmente lo aprobaba. El arquitecto responsable de la obra presentaba posteriormente sucesivas memorias semanales y relaciones juradas de los gastos, que después de revisadas por el contador eran remitidas al tesorero para que se entregara una libranza u orden de pago.

En principio todo estaba bien previsto, pero era posible aumentar los costos presentando diferentes circunstancias que surgían durante el desarrollo de la construcción, o alargando el tiempo de los trabajos. Fue notoriamente lo ocurrido en varias obras emprendidas por Constanzó entre 1779 y 1783, que por situaciones incidentales y peticiones consecutivas de ampliación del proyecto inicial derivaron en un enorme exceso de 127319 pesos. El caso podría haber dado lugar a procesos judiciales contra los responsables, pero el Tribunal de Cuentas demoró su dictamen nada menos que catorce años; para cuando el resultado llegó a la metrópoli los responsables del quebranto habían ya fallecido. Era tal la ineficiencia contable que no habría sido posible sin complicidades o, al menos, simpatías. Las complicaciones jurídicas debieron parecerle tan grandes al virrey Ruiz de Apodaca que en 1820 optó por recordar a todos los implicados el obligatorio cumplimiento de las ordenanzas, aceptar el gasto realizado y evitar lo que llamó "depredación al erario", además de convocar obligatoriamente a concurso público cuando hubiera alguna obra de consideración, de modo que el contratista (y no la Real Hacienda) corriera con todos los gastos que pudieran sobrevenir. ${ }^{16}$

\section{MAQUINARIA Y HERRAMIENTAS}

Las máquinas y herramientas eran recursos de la mayor importancia, que se hicieron aún más necesarios y urgentes en razón de que la acuñación se hizo tecnológicamente más compleja a partir de 1732. La deficiente ca-

${ }^{16}$ Casa de Moneda (vol. 308, exp. 7, fs. 22-27). Archivo General de la Nación, México. 
lidad en la fabricación o mantenimiento de cualquier equipo podía afectar a todo el proceso productivo, puesto que la producción estaba divida en fases necesariamente consecutivas. En estos aspectos también puede apreciarse (al igual que en el caso del proyecto arquitectónico de Peinado Valenzuela) cierto localismo tecnológico, y el interés por defender lo que en términos modernos sería "la materia de trabajo". Esto pudo apreciarse muy bien cuando se mandó traer de España, a gran costo, un molino desarmado (con un modelito a escala, para que los indianos supieran qué hacer con las piezas), prensas de volante, máquinas de corte y herrajes varios para la construcción de diversas máquinas. Los peritos consultados lo tomaron a mal, dijeron que las piezas eran de mala calidad y no podrían utilizarse sin grandes ajustes, y que todo podía fabricarse localmente, de mejor calidad y a menor costo (Pérez, 1992, p. 347).

La cuestión de "comprar localmente" o traer las máquinas desde España volvió a aparecer a raíz de una consulta del virrey segundo conde de Revillagigedo al superintendente, en febrero de 1791, en el sentido de que podrían obtenerse ahorros trayendo piezas desde la metrópoli, al ser allá los materiales y los jornales menos caros. Gil, que para entonces aunaba las funciones de encargado del grabado, director de la Academia de Artes y fiel administrador, opinó el 11 de marzo siguiente que no convenía, porque además de los costos y dificultades del transporte, podría haber problemas de ajuste en las medidas y diseños, y bastaría la variación de un ápice para que las piezas fuesen inútiles. A lo sumo, pensaba que convendría traer acero y hierro de las afamadas fundiciones vizcaínas, porque en la ceca se gastaban anualmente hasta 100 quintales de lo uno y 143 de lo otro, así como algunas piezas muy voluminosas de los volantes, que podrían acabar de tornearse en la misma Real Casa de Moneda. Gil mencionaba un dato muy interesante: que sólo en el mantenimiento y sustitución de las partes y herramientas de hierro y acero se gastaban anualmente 16325 pesos, sin contar las piezas menudas que se fabricaban o reparaban en la propia ceca. ${ }^{17}$

En efecto, había en el establecimiento para estos fines (y otros menesteres cotidianos) talleres de herrería y carpintería muy capaces y bien organizados. Otro asunto era el mantenimiento o fabricaciones que por su entidad requerían montar un taller y contar con numerosos operarios. Lo adecuado habría sido contratar a un maestro artesano examinado, de los que había muchos en la ciudad, con talleres celosamente supervisados por sus respectivos gremios. Así se procedió en 1747, por ejemplo, para la construcción de cien hileras, que eran bancos de madera provistos de un engranaje, con tenazas que sujetaban la barra metálica, previamente

${ }^{17}$ Casa de Moneda (vol. 147, exp. 9, fs. 71-93). Archivo General de la Nación, México. Un quintal equivalía aproximadamente a $46 \mathrm{~kg}$. 
recalentada para que tuviera cierta ductilidad. El operario impulsaba el engranaje mediante grandes manijas para hacer pasar el metal por orificios y lograr así que tuviera el grosor deseado para la amonedación. Para construir estas hileras (así como cuatro docenas de crisoles, utilizados en los hornos de fundición) se contrató a un maestro herrero, quien a su vez se valió de 16 maestros artesanos y jornaleros, entre carpinteros, herreros y limadores. ${ }^{18}$

No obstante, el superintendente, y sobre todo el contador, que siempre estaban procurando realizar economías, recurrían frecuentemente a un procedimiento sui géneris: acordaban con alguno de los peritos de la propia ceca que se ocuparían de ser "pagadores" de la obra, o sea responsables de contratar operarios y de llevar a cabo el encargo. Así se hizo, por ejemplo, con la necesaria renovación de los seis molinos (grandes estructuras de complicados engranajes, que ocupaban dos pisos) que en 1778, después de más de 40 años de servicio, necesitaban de urgente reparación. La obra fue presupuestada inicialmente en 8000 pesos, pero en vez de contratarla fuera del establecimiento el superintendente nombró como director y pagador al guardavista (una especie de capataz) Joaquín de Luzuriaga, con una gratificación de un peso adicional diario sobre su jornal habitual. Luzuriaga trabajó durante más de un año en esta obra, con carpinteros y herreros que recibían seis reales diarios (lo cual indica que eran artesanos de cierta calificación) pagados, como era costumbre, según memoria y relación jurada y de la que hacía entrega semanalmente. El presupuesto final se redujo de esta manera a 5813 pesos, un ahorro de algún interés para las finanzas reales. ${ }^{19}$

\section{Combustible}

La Real Casa de Moneda tenía numerosos hornos que requerían abasto suficiente y continuo de combustible. No era todo de la misma condición, porque el tipo dependía de la viveza del fuego requerido, o de la conveniencia de tener una fuente de calor duradera y graduable (véase cuadro 2).

Las autoridades siempre procuraron asegurar un aprovisionamiento de carbón continuo, de buena calidad, en suficiente cantidad y, si era posible, a buen precio. La oferta descendía inevitablemente en época de lluvias -cuando era difícil producirlo- o cuando los indios, que eran los principales proveedores, estaban ocupados en siembras y cosechas. Por esta razón, con cierta frecuencia se mencionaba la posibilidad de esta-

\footnotetext{
${ }^{18}$ Casa de Moneda (vol. 27, exp. 3, fs. 158-165). Archivo General de la Nación, México.

${ }^{19}$ Casa de Moneda (vol. 388, exp. 2, fs. 7-79). Archivo General de la Nación, México.
} 


\section{CUADRO 2. VARIEDADES DEL COMBUSTIBLE UTILIZADO EN LA CASA DE MONEDA}

Proceso industrial

Ensaye

Primera fundición

Herrería

Fundición

Hornillas de recocimiento

Blanquimiento

\section{Combustible}

Leña de cedro

Leña de cedro

Leña de oyamel, carbón de ocote

Carbón de oyamel

Carbón de ocote

Carbón de ocote

Nota: El ensaye consistía en la comprobación de la ley de los metales mediante su fundición en una hornilla y posterior pesaje en una balanza de precisión. El recocimiento implicaba recalentar las barras de metal para mantener su ductilidad e impedir que se agrietaran al someterlas a distintos procesos físicos. En el blanquimiento, las monedas ya acuñadas se ponían a hervir en una solución ácida para eliminar manchas y asegurar su brillo característico.

Fuentes: elaborado con base en la compilación de información fragmentaria y dispersa de los contratos contenidos en los archivos mencionados en notas a pie de página 20 a 40 . Los contratos a continuación expuestos, véanse referencias a pie de página.

blecer una bodega para tener algunas reservas. Finalmente así se hizo: en 1802 se construyó un almacén fuera del establecimiento para evitar posibles incendios, en el barrio indígena de Santa Cruz (entre la iglesia de la Santísima y San Lázaro). ${ }^{20}$

El carbón en sus diferentes variedades fue proporcionado inicialmente por Atlapulco, un pueblo otomí ubicado en la entonces muy boscosa Sierra de las Cruces, al poniente de la ciudad. Según sus tradiciones locales, realizaban el abastecimiento a la Real Casa de Moneda desde su fundación, en 1535. Su labor fue reconocida por los virreyes, que les dieron mercedes sobre tierras boscosas y los exentaron de acudir al servicio destinado a las minas. De hecho, en esta relación no mediaba ningún contrato, sino simplemente la mutua conveniencia y la costumbre "inmemorial" (Castro, 2008, pp. 669-720).

A partir del inicio de la administración gubernamental, los nuevos funcionarios comenzaron a exigir contratos formales entre la Real Casa de Moneda y los oficiales de república del pueblo, que para el caso actuaban como representantes de una especie de empresa comunitaria. Las ventas, sin embargo, eran individuales, y cada carga se registraba y pagaba separadamente. El guardavista de cada oficina daba a cada introductor una bole-

\footnotetext{
${ }^{20}$ Casa de Moneda (vol. 518, exp. 636). Archivo General de la Nación, México.
} 
ta, indicando la cantidad recibida, y el guardamateriales contaba y pagaba el conjunto cada sábado. Aunque era frecuente hablar de los "miserables indios carboneros", el trato movía cantidades respetables. En 1795 el contador de la ceca calculó que el establecimiento consumía 22600 cargas anuales de carbón. ${ }^{21}$ Una carga (compuesta de cuatro costales) se pagaba entre seis y ocho reales, aunque en el contexto de la escasez provocada por la revolución de independencia llegó hasta diez o doce reales. ${ }^{22}$ Por estas razones, el abasto atrajo a otros pueblos de indios, como Chimalpa (un sujeto o dependencia de Tacuba), que tuvo esta "conveniencia" en 1776, aunque se desinteresaron algunos años después, ${ }^{23}$ y el de Tilapa, un sujeto de Atlapulco que se separó de su cabecera y en 1788 obtuvo su propio contrato. ${ }^{24}$ Aún más, el negocio tentó a grandes propietarios españoles, como el condado de Miravalles (una familia de latifundistas, por entonces casi en quiebra) que desde 1786 estuvo pagando con carbón un adeudo que tenía con la Real Hacienda. ${ }^{25}$ Otros propietarios hispanos también tuvieron contratos de abasto, como José Fernández de Alfaro, dueño de hacienda en Azcapotzalco, entre 1773 y 1794; y Manuel Caro del Castillo, hacendado de la jurisdicción de Tacuba, entre 1765 y $1780 .{ }^{26}$

En los contratos, los pueblos de indios se comprometían a abastecer el carbón a un precio fijo y ponían como aval del cumplimiento sus bienes de comunidad. Renunciaban además a sus privilegios legales como menores, prometían cumplir con el contrato lisa y llanamente, y en caso de controversia se sometían a las determinaciones del superintendente. ${ }^{27}$ La Real Casa de Moneda, como puede verse, no corría ningún riesgo. Por otro lado, los oficiales de la ceca procuraban tratar bien a los indios carboneros, por ejemplo otorgando préstamos a sus cabildos, aunque hacerlo con fondos de la Real Hacienda era visto con desaprobación. La vía indirecta era efectuarlos por vía de "adelanto", a pagar con carbón. ${ }^{28}$ En esto, las autoridades actuaban ante los indígenas, como era común entre los funcionarios virreinales, con una especie de paternalismo autoritario.

Respecto a la leña, durante casi 70 años los proveedores fueron tres generaciones consecutivas de la familia Reyes, indios principales y caciques de Chalco, que aprovechaban los montes de la región. Se trataba de la

${ }^{21}$ Casa de Moneda (vol. 147, exp. 30, fs. 198-215). Archivo General de la Nación, México.

${ }^{22}$ Casa de Moneda (vol. 107, exp. 4, fs. 22-39) y (vol. 74, exp. 5, fs. 42-74). Archivo General de la Nación, México.

${ }^{23}$ Casa de Moneda (vol. 107. exp. 14, fs. 318-325). Archivo General de la Nación, México.

${ }^{24}$ Casa de Moneda (vol. 134, exp. 25, fs. 343-346). Archivo General de la Nación, México.

${ }^{25}$ Casa de Moneda (vol. 147, exp. 8, fs. 65-70). Archivo General de la Nación, México.

${ }^{26}$ Casa de Moneda (vol. 355, exp. 6, fs. 140-145). Archivo General de la Nación, México.

${ }^{27}$ Casa de Moneda (vol. 74, exp. 5, fs. 71-73). Archivo General de la Nación, México.

${ }^{28}$ Por ejemplo Casa de Moneda (vol. 134, exp. 11, fs. 150-230). Archivo General de la Nación, México. 
leña "grande", porque la "chica" se compraba cómodamente en la misma ciudad, en el puente llamado precisamente "de la leña", junto a la acequia real, a quienes la traían en canoas para venderla al primer interesado. En 1737 Lucas de los Reyes tuvo dificultades para entregar las cantidades necesarias, debido a que había estado enfermo y posteriormente preso en la cárcel por "incontinencia" (es decir, amancebamiento o adulterio). El superintendente mandó aprehenderlo y embargarle sus bienes por incumplimiento. Aunque después fue liberado y se le permitió continuar con el trato, ya no se le tuvo confianza. A pesar de sus ruegos y recordatorio de los largos servicios de su familia, ya no pudo mantener la exclusividad. El superintendente decidió celebrar un contrato con Ignacio de Aristizábal, dueño de hacienda en Chalco, para que entregara la leña de cedro. ${ }^{29} \mathrm{En}$ fechas posteriores, realizó contratos con diversos proveedores, todos españoles, como Francisco Hernando y Llaguno y sus sucesores, vecinos de Naucalpan; y con Francisco Sastre y Pascual, vecino de México (quien también proveyó carbón, ocasionalmente). ${ }^{30}$

El Apartado de Oro contrataba de manera separada el abasto de su leña, y acostumbró realizarlo con Vicente de Arroyave, un propietario de Chalco y luego con sus herederos. Los Arroyave consiguieron notables facilidades, como un contrato a doce años, el derecho a poner las armas reales en su casa y una insignia de la Real Hacienda en las grandes canoas que recorrían los canales para llevar la leña hasta la puerta misma del Apartado. El negocio motivaba ambiciones, y en particular los Arroyave se quejaron de que los "regatones" o revendedores forzaban a los indios conductores a venderles la leña (que ellos cotizaban a menor precio del común en el mercado), y cuando se negaban les tiraban la carga o les quitaban las bestias de carga. ${ }^{31}$

La leña se pagaba a un peso la carga de 400 "palos", que era lo que llevaba una mula, aunque ocasionalmente llegó a pagarse hasta tres pesos. Los contratos fueron por cinco años, y los "leñeros" debían entregar los palos de acuerdo con una muestra que les daba el guardamateriales. El proveedor podía solicitar ayuda a la Real Casa de Moneda en caso de que necesitara gente para el corte y traslado, que podía obtenerse mediante el sistema de "repartimiento" o trabajo forzoso (pero retribuido) de los pueblos indios. También podía pedir anticipos del pago, con las fianzas correspondientes. Como ocurría con todos los contratos, el firmante se sometía a

\footnotetext{
${ }^{29}$ Casa de Moneda (vol. 195, exp. 2, fs. 16-74). Archivo General de la Nación, México.

${ }^{30}$ Casa de Moneda (caja 718, exp. 139, 5 fs.) Archivo General de la Nación, México.

${ }^{31}$ Casa de Moneda (vol. 79, exp. 3, fs. 24-42). Archivo General de la Nación, México.
} 
las determinaciones del superintendente en caso de que se ofreciera algún litigio, renunciando a cualquier otro fuero que pudiera convenirle. ${ }^{32}$

\section{FUERZA MOTRIZ}

En la Casa de Moneda de Segovia - que fue hasta el siglo XVIII la más avanzada tecnológicamente del imperio español- se utilizaba la fuerza hidráulica para mover molinos y prensas. En México esto no era posible, porque aunque la tecnología era bien conocida, la ceca se ubicó anexa al palacio virreinal, lejos de toda corriente de agua. En los primeros años esto no fue ningún problema, porque la acuñación era artesanal, a martillo. No obstante, fue necesario utilizar mulas como fuerza motriz cuando en 1732 se introdujeron los grandes molinos y prensas mecánicas para aplanar las barras de metal. Por esta razón había en la ceca un "patio de mulas", con su correspondiente capataz, muleros, arreadores, establos y el correlativo gasto en forraje. Cuando Alejandro de Humboldt visitó la ceca en 1803, encontró que había diez molinos, movidos por 60 "caballerías"; es de suponer que se rotaban para evitar su agotamiento, porque la labor era muy pesada (Humboldt, 1966, pp. 457-458). De hecho, periódicamente la ceca compraba otros animales, porque los existentes estaban ya inútiles para la labor. Los proveedores eran comerciantes que mantenían las mulas en propiedades vecinas, como la hacienda de Portales, donde podían verse pastar en espera de compradores interesados. En una ciudad que era el mayor centro mercantil del virreinato, había siempre compradores entre los mercaderes, arrieros y el público en general; era un trato muy activo.

En la Real Casa de Moneda era el fiel administrador (como director de la fundición) quien presentaba la necesidad de la compra y habitualmente proponía un vendedor, recomendando el buen estado de las bestias y un razonable costo. El contador, acompañado del fiel, acudía a ver los animales y procuraba negociar un buen precio con el dueño. No lo conseguían fácilmente, porque en este caso el volumen de adquisiciones era limitado, y la demanda urbana era muy grande. Así se hizo por ejemplo en 1814 cuando el fiel administrador José Antonio Camblor gestionó la compra de 50 mulas a 40 pesos cada una -un precio que se mantiene en varias transacciones similares, sin rebajas. ${ }^{33}$ Para cerrar el ciclo comercial, los aniMéxico.

${ }^{32}$ Casa de Moneda (vol. 718, 3a. serie, exps. 141, 142 y 143). Archivo General de la Nación,

${ }^{33}$ Casa de Moneda (vol. 169, exp. 26, fs. 353-358). Archivo General de la Nación, México. 
males "inservibles" o enfermos se remataban al mejor postor, porque en la Real Casa nada se desperdiciaba y siempre aparecía algún comprador. ${ }^{34}$

Evidentemente, las mulas requerían de alimento. La paja podía adquirirse libremente en la llamada Plazuela de la Paja, situada frente al Hospital de Jesús (hoy plaza Primo de Verdad). Las autoridades, sin embargo, preferían la seguridad de un contrato, como el realizado con Agustín Sánchez de la Concha, quien tuvo este acuerdo durante casi 20 años, al precio de un real cada arroba, que era el habitual. ${ }^{35}$

La cebada, que también se daba a estos animales, se compraba asimismo en el mercado urbano, pero a veces variaba su precio de acuerdo con las estaciones del año y esto inquietaba a los administradores. Por eso optaban por realizar contratos como el efectuado en 1810 con el capitán José Manuel Aréchega, hacendado de Apan, por 1000 cargas, de las que entregaría 50 cada semana, a cuatro pesos dos reales cada una. A diferencia de otros insumos, en este contrato no se establecía la duración del acuerdo, sino la cantidad objeto de la transacción. ${ }^{36}$

\section{EL COBRE}

Las monedas acuñadas no eran de oro o de plata puros, se les agregaba siempre una "liga" de cobre para darle mayor resistencia al desgaste y además obtener la ley mandada por las ordenanzas. A partir de 1729, las monedas de plata tuvieron ley de once dineros y por lo tanto $8.33 \%$ de cobre. Aunque este porcentaje no parezca grande, multiplicado por toda la producción de la ceca representaba una cantidad de cierta consideración. También, en pequeñas cantidades, el "magistral" (sulfato de cobre) era empleado para refinar los recortes y limaduras de plata que quedaban revueltas con carbón y otros desperdicios, de manera que pudieran reintegrarse al proceso de acuñación.

Como bien ha explicado Elinore M. Barrett (1978), el cobre se extraía mayormente del cerro de Inguarán, en Michoacán. De ahí era enviado al pueblo de Santa Clara, donde se hacía una primera refinación, fundición y vaciado en planchas que eran enviadas a lomo de mula a la capital. La corona siempre estuvo muy atenta a este trato, porque además de ser indispensable para la acuñación, el cobre era uno de los componentes del bronce, una aleación que se utilizaba entre muchas otras cosas para la fabricación de cañones. Por este motivo, en 1613 el gobierno se apropió

\footnotetext{
${ }^{34}$ Casa de Moneda (vol. 141, exp. 16, fs. 163-175). Archivo General de la Nación, México.

${ }^{35}$ Casa de Moneda (vol. 388, exp. 2, fs. 7-79). Archivo General de la Nación, México.

${ }^{36}$ Casa de Moneda (vol. 2, exp. 49, fs. 339-340). Archivo General de la Nación, México.
} 
de la mina que hasta entonces había sido explotada por los indios y la entregó en condiciones monopólicas a un asentista, que adicionalmente recibía el cargo de teniente de alcalde mayor de Santa Clara. El precio acordado para la entrega en la ciudad de México fue de 16 pesos por quintal entre 1718 y 1780, año en que subió a 18 pesos (Barrett, 1978, pp. 28-29, 61). El aprovisionamiento fue irregular, y en 1792 se determinó concluir el "asiento", dejando a cualquier persona que libremente extrajera y refinara el cobre. Sin embargo, la Real Hacienda sería la única compradora, distribuyendo el metal a las instituciones y personas interesadas. En otros términos, un monopolio de la producción fue sustituido por uno de la adquisición (Barret, 1978, pp. 40-42). Como comenta José Enrique Covarrubias (2000, pp. 26-30), el precio fijo ahogaba la producción y fomentaba el contrabando, aunque se hicieron algunos ajustes para hacer que la producción fuese más rentable, de modo que hacia finales del siglo se cotizó en 22 pesos el quintal. Hacia 1799, la ceca requería aproximadamente de 2000 quintales anuales. Al precio vigente en ese año equivaldría aproximadamente a unos 44000 pesos (Barret, 1978, pp. 47-61). En 1809 el virrey Pedro de Garibay, en el contexto de la gran demanda existente en España de este mineral "estratégico" en razón de la guerra contra los franceses, decidió establecer la entera libertad del trato como mejor medio para asegurar el abasto. ${ }^{37}$

El problema para la Real Casa fue siempre la calidad. Un poco por torpeza y otro por malicia, los asentistas, y luego los mineros particulares, entregaban las planchas de cobre mezcladas con ceniza, carbón, e incluso piedras. Además, el cobre de Inguarán venía asociado con azufre y arsénico, lo cual era inconveniente porque podía afectar la calidad de la plata. Por esta razón, era necesaria una segunda refinación. En un tiempo hubo en la ceca un maestro ensayador de cobre; pero al aumentar las labores y con ellas la necesidad del mineral, los administradores concluyeron que en el establecimiento no había espacio suficiente para instalar oficinas de fundición a gran escala. Así, optaron por contratar la labor con terceros, mediante remate y una convocatoria que se fijaba en rotulones o avisos en lugares públicos. El contratista fue Manuel Antonio del Castillo, un comerciante de la ciudad desde 1771 hasta su muerte en $1796 .{ }^{38}$ Entre 1797 y 1807 el "afinador de cobres", como se le llamaba, fue Salvador de Vega, alguien que era "del oficio", porque era maestro latonero y fundidor. Vega acordó que entregaría el cobre refinado en varilla, a seis pesos dos reales por quintal, y a real y medio la libra de retalla o recortes. ${ }^{39}$ Los rendimien-

\footnotetext{
${ }^{37}$ Casa de Moneda (vol. 166, exp. 20, fs. 343-347). Archivo General de la Nación, México.

${ }^{38}$ Casa de Moneda (vol. 193, exp. 5, fs. 308-361). Archivo General de la Nación, México.

${ }^{39}$ Casa de Moneda (vol. 661, exp. 100, fs. 1-6). Archivo General de la Nación, México.
} 
tos del contrato eran atractivos: en 1807, año en que se procesaron 1266 quintales, el concesionario obtuvo 7662 pesos de ingresos, aunque desde luego debía descontar los gastos de combustible y mano de obra. ${ }^{40}$

Precisamente en 1807, cuando concluyó el contrato con Vega, el fiel administrador José Antonio Camblor propuso que no se renovara. En su opinión, los contratistas siempre buscaban rebajar los costos, lo cual redundaba en pobre calidad, gastos adicionales y pérdida de tiempo. En particular, el cobre mal refinado causaba que no se "ligara" bien con el oro y la plata, lo cual provocaba que las barras se "agriaran" y endurecieran. $\mathrm{Al}$ pasar por las prensas, se agrietaban o quebraban, y había que volverlas a fundir, con las demoras y gastos consiguientes. Proponía que se realizara la afinación de cuenta de la misma Real Casa. Sugirió para ello un terreno propiedad del Ayuntamiento, en el barrio de Santa Cruz (no muy lejos, pasando la iglesia de la Santísima), donde había espacio suficiente para poner hornos y demás talleres necesarios. Pensaba, además, que los gastos podrían así fácilmente reducirse a la mitad.

Después de algunos experimentos, así lo aprobó en marzo de 1809 el superintendente marqués de San Román. El arquitecto Velázquez calculó los costos (incluyendo la compra del local), en 16978 pesos, pero después los incrementó a 30 567, alegando diversas circunstancias. La modificación provocó la molestia del virrey Garibay, que para entonces estaba muy presionado para enviar todos los recursos posibles a la península. El alto funcionario mandó suspender los trabajos además de amonestar formalmente a Velázquez, porque ya había hecho lo mismo en otras construcciones públicas. Tuvo que volver a intervenir el superintendente, insistiendo en la necesidad de las obras y argumentando que los costos se recuperarían en breve. Un nuevo virrey, el arzobispo Lizana y Beaumont, dio finalmente su aprobación. A fines de 1810 la obra estaba casi terminada, aunque algunos detalles no se concluyeron hasta 1812, con los consabidos costos adicionales. ${ }^{41} \mathrm{~A}$ fin de cuentas, la decisión tomada se mostró muy pertinente, porque a partir de 1814 se determinó comenzar a acuñar moneda de cobre para suplir la escasez de circulante provocada por la guerra de Independencia, y por ende se requirieron mayores cantidades de este metal (Soria, 1994a, pp. 229-231).

\footnotetext{
${ }^{40}$ Casa de Moneda (vol. 356, exp. 8, fs. 210). Archivo General de la Nación, México.

${ }^{41}$ Casa de Moneda (vol. 356, exp. 8, fs. 286-312). Archivo General de la Nación, México.
} 


\section{Conclusiones}

El impacto de las operaciones de la Real Casa de Moneda en la economía era considerable en la ciudad y el Valle de México. No era resultado, desde luego, de una política gubernamental deliberada (el concepto de "inversión gubernamental" aún no aparecía), sino el resultado indirecto de las operaciones de acuñación.

El establecimiento prefería realizar contratos a largo plazo para asegurar un abasto continuo, de buena calidad y precio conveniente, cuyas condiciones y pagos eran objeto de supervisión y cuidadosa contabilidad. En este sentido, muestra la introducción de principios racionales en el abastecimiento y administración de una gran industria. En un entorno productivo en el que predominaban los criterios improvisados o la costumbre, la ceca destacaba por una preocupación por la eficiencia y el ahorro en los gastos. También resalta que las autoridades fueron flexibles para asegurar sus requerimientos: podían concesionar el abasto de insumos o servicios, producirlos en el mismo establecimiento o dar comisión a uno de sus propios peritos. Su criterio era enteramente pragmático, no tenían preferencias de principio, podían hacer experimentos y evaluar los méritos y desventajas de los diferentes procedimientos. Por otro lado, la racionalidad administrativa tenía sus límites: en algunos casos los contratistas pudieron encontrar maneras indirectas de aumentar los costos, sobre todo cuando se trataba de obras de infraestructura, y encontraron para ello ciertas tolerancias.

Una revisión de los proveedores hace evidente que era un trato en el que no participaban los grandes comerciantes de México, ni tampoco (con alguna excepción incidental) los mayores hacendados. No era un circuito de inversiones que tuviera efectos macroeconómicos notables; su relevancia era, sobre todo, local. Los contratistas fueron arquitectos o "maestros" de arquitectura, con sus respectivas cuadrillas; medianos propietarios, cuyos bienes consistían en terrenos boscosos ricos en madera; maestros artesanos, que ofrecían su experiencia y la habilidad de sus oficiales para refinar el cobre; y pueblos de indios que contaban con los recursos forestales necesarios para el abasto del carbón.

Estos contratos no eran exactamente entre agentes económicos que actuaran en igualdad de condiciones, siguiendo las reglas de la oferta y la demanda. En este sentido, difícilmente serían aplicables los modelos propios para comprender el funcionamiento de las empresas modernas. La ceca utilizaba a su favor el hecho de ser una manufactura real, y en caso de disputas, el superintendente era juez y parte. Incluso cuidaba que los pueblos de indios renunciaran a sus privilegios de menores, y pusieran como garantía sus bienes de comunidad, a pesar de que en teoría estaban muy protegidos 
por las leyes. Los contratistas privados podían alegar su antigüedad y buenos servicios, procurando que la relación fuese personal y recíproca, pero el establecimiento seguía principios de eficiencia y rentabilidad. No dudaba en cancelar un contrato o buscar otros proveedores cuando le conviniera. También podía imponer condiciones, porque el volumen de sus adquisiciones era tal que reducía al proveedor a una condición de dependencia. Aun así, eran concesiones muy ambicionadas por la continuidad y puntualidad del pago, y suscitaban frecuentes rivalidades y ambiciones locales.

Como habrá podido apreciarse, el estudio de una real manufactura permite una mejor consideración de los cambios económicos e institucionales en distintos momentos de la historia novohispana. También hace posible una mejor perspectiva de sus efectos sobre un conjunto de personas, empresas y corporaciones que dependían del establecimiento. Es un tema que bien vale atender, y que podría abrir perspectivas de interés sobre los efectos indirectos del gasto público en economías y sociedades premodernas.

\section{LISTA DE REFERENCIAS}

BARRETt, E. M. (1978). The Mexican colonial copper industry. Albuquerque: University of New Mexico.

Castro, F. (2008). San Pedro Atlapulco y la Real Casa de Moneda: las vicisitudes de una empresa comunitaria. Historia Mexicana, 57(3), 669-720.

Castro, F. (2012). Historia social de la Real Casa de Moneda de México. México: Universidad Nacional Autónoma de México.

Céspedes del Castillo, G. (1996). Las casas de moneda en los reinos de Indias (vol. 1, Las cecas indianas en 1536-1825). Madrid: Fábrica Nacional de Moneda y Timbre/ Museo Casa de Moneda.

Covarrubias, J. E. (2000). La moneda de cobre en México, 1760-1842: un problema administrativo. México: Universidad Nacional Autónoma de México/Instituto de Investigaciones Dr. José María Luis Mora.

DEAns, S. (1992). Bureaucrats, planters and workers: The making of the tobacco monopoly in Bourbon Mexico. Austin: University of Texas.

ElHÚYAR, F. DE (1979). Indagaciones sobre la amonedación en Nueva España (ed. facs.). México: M. A. Porrúa.

Encinas, D. DE (1945-1946). Cedulario indiano (ed. Alfonso García Gallo, 4 vols.). Madrid: Instituto de Cultura Hispánica.

FLORES, E. (mayo-agosto, 2008). Acuñación y contrabando de oro en Nueva España (1777-1822). Historias, 70, 39-54.

Flores, H. (2007). Reflexiones sobre los tratados de arquitectura y su influencia en la Nueva España durante la primera mitad del siglo XVIII: los testimonios del arquitecto José Eduardo 
de Herrera en torno a la construcción de la Real Casa de Moneda (Tesis de maestría en Historia). Universidad Nacional Autónoma de México, México.

FonseCA, F. DE y URRUTIA, C. DE (1978). Historia general de Real Hacienda (6 vols.). México: Secretaría de Hacienda y Crédito Público.

Gómez, A. (1979). Las visitas de la Real Hacienda novohispana en el reinado de Felipe V, 1710-1733 (pról. de Luis Navarro García). Sevilla: Escuela de Estudios Hispano-Americanos.

GonzÁlEz, G. (1991). González Velázquez y el neoclásico en la Nueva España. Boletín de Monumentos Históricos, 15, 30-39.

GonzÁlez, P. (1997). Creación de casas de moneda en Nueva España. Alcalá: Universidad de Alcalá.

Herrera, I. (mayo-agosto, 1994). Estadísticas históricas de acuñación en México. Origen y manejo de las cifras: la época colonial y los primeros años del México independiente. Historias, 58, 105-124.

Hirschman, A. O. (1973). La estrategia del desarrollo económico (3a. reimp.). México: Fondo de Cultura Económica.

Hoberman, L. (1991). Mexico's merchant elite, 1590-1660: Silver, State, and Society. Durham: Duke University.

Humboldt, A. DE (1966). Ensayo político sobre el reino de la Nueva España (ed. Juan Antonio Ortega y Medina). México: Porrúa.

IbARRA, A. (2010). La edad de plata: mercados, minería y agricultura en el periodo colonial tardío. En S. KunTz (coord.), Historia económica general de México. De la colonia a nuestros días (pp. 211-243). México: El Colegio de México/Secretaría de Economía.

León, N. (1922). El Santo Desierto de Cuajimalpa o Desierto de los Leones. México: Imp. Manuel León Sánchez.

Marchena, J. (1979). La financiación militar en Indias: introducción a su estudio. Anuario de Estudios Americanos, 36, 93-110.

MARICHAL, C. (1999). La bancarrota del virreinato: 1780-1810. La Nueva España y las finanzas del imperio español, 1780-1810. México: Fondo de Cultura Económica/El Colegio de México.

Moncada, J. O. (1994). El ingeniero Miguel Constanzó. Un militar ilustrado en la Nueva España del siglo XVIII. México: Universidad Nacional Autónoma de México.

Orozco y Berra, M. (2004). Moneda en México. En A. Pi-Suñer (coord.), México en el Diccionario Universal de Historia y de Geografía (vol. 3). México: Universidad Nacional Autónoma de México.

PÉrez, L. (2003). Familia, poder, riqueza y subversión: los Fagoaga novohispanos, 1730-1830. México: Universidad Iberoamericana/Real Sociedad Bascongada de los Amigos del País.

Pérez, F. DE (1992). La Casa de la Moneda de Sevilla: su historia. Sevilla: Universidad de Sevilla/Fundación Fondo de Cultura de Sevilla. 
Recopilación de las leyes destos reynos, hecha por mandado de la Magestad Católica del Rey don Felipe Segundo nuestro señor (1982) (ed. facs.). Valladolid: Lex Nova.

Recopilación de leyes de los reynos de las Indias (1973) (pról. R. Menéndez y Pidal, estudio preliminar J. M. Manzano). Madrid: Cultura Hispánica.

Rosenmüller, CH. (2008). Patrons, partisans, and palace intrigues: The court society of colonial Mexico, 1702-1710. Calgary: University of Calgary.

Romano, R. (1998). Moneda, seudomonedas y circulación monetaria en las economías de México. México: Fondo de Cultura Económica/El Colegio de México.

SEMPAT, C. (1998). La organización económica espacial del sistema colonial. En J. SiLVA y J. López (coords.), Mercado interno en México. Siglos XVIII-XIX. México: Instituto de Investigaciones Dr. José María Luis Mora/El Colegio de Michoacán/El Colegio de México/Universidad Nacional Autónoma de México.

Soria, V. M. (1994a). La Casa de Moneda de México bajo la administración borbónica, 17331821. México: Universidad Autónoma Metropolitana.

Soria, V. M. (1994b). La incorporación del Apartado del Oro y la plata a la Casa de Moneda y sus resultados de operación, 1778-1805. Historia Mexicana, 44(2), 269-298.

Tepaske, J. (1976). La Real Hacienda de Nueva España. La real caja de México, 1576-1816. México: Instituto Nacional de Antropología e Historia.

URIBe, E. (1990). Tolsá: Hombre de la ilustración. México: Consejo Nacional para la Cultura y las Artes/Instituto Nacional de Bellas Artes.

VAldeZ, V. (1987). De las minas al mar. Historia de la plata mexicana en Asia, 1565-1834. México: Fondo de Cultura Económica.

VAlle, G. DEL (2011). Bases del poder de los mercaderes de plata de la ciudad de México. Redes, control del Consulado y de la Casa de Moneda a fines del siglo XVII. Anuario de Estudios Americanos, 68(2), 565-598.

Weber, M. (1984). Economía y sociedad (ed. Johannes Winckelmann, 7a. reimp. de la 2a. ed.). México: Fondo de Cultura Económica.

ZAMORA y CORONADO, J. M. (1844-1849). Biblioteca de legislación ultramarina: en forma de diccionario alfabético. Madrid: Imprenta de Alegría y Charlain. 